\title{
Gestão em rede e apoio institucional: caminhos na tessitura de redes em saúde mental no cenário regional do Sistema Único de Saúde (SUS)
}

Almeida $A B$, Aciole GG. Network management and institutional support: pathways in assembling mental health networks within the regional scenario of the Brazilian Health System (SUS). Interface (Botucatu). 2014; 18 Supl 1:971-81.

This report is a cartographic record of institutional support at a state health department, in organizing a regional mental health network. Institutional support is a strategy of the National Humanization Policy in healthcare networks and a device for fostering comanagement spaces. This report is guided by three strands: collective production and affection in meetings between managers and workers; action linking institutional support, offers under analysis and collegiate implications; and desires for and collective construction of investment objects. With the experience of the support function as a pathway for linking and extracting the meanings of this action through the desires that mobilize it, we take a critical look at the strengths and weaknesses of institutional subjects and their roles in the collegiate production of mental health care.

Keywords: Healthcare management. Institutional support. Mental health.
Este relato é um registro cartográfico do apoio institucional junto a uma Secretaria Estadual de Saúde na articulação da rede regional de Saúde Mental. O apoio institucional é uma estratégia da Política Nacional de Humanização nas redes de atenção à saúde e dispositivo de fomento de espaços de cogestão. O relato está pautado em três eixos: a produção de coletivos e os afetamentos dos encontros entre gestores e trabalhadores; a ação articuladora do apoio institucional, as ofertas na análise e a implicação colegiada; e os desejos e a construção coletiva dos objetos de investimento. Com a vivência da função apoio como caminho da articulação e extraindo os sentidos desse fazer pelos desejos que mobilizam o agir, elaborou-se um olhar crítico para as fortalezas e fragilidades dos sujeitos institucionais e dos seus papéis na produção colegiada do cuidado em saúde mental.

Palavras-chave: Gestão em saúde. Apoio institucional. Saúde mental. 


\section{Introdução}

O escopo político constitucional de direito à saúde, expresso no Sistema Único de Saúde (SUS), vem se constituindo por meio de estratégias envolvidas na ampliação das relações intergovernamentais. No entanto, pressupostos previstos constitucionalmente ainda não estão plenamente adequados ao cotidiano da gestão e dos serviços de saúde, como o princípio organizativo da regionalização, que impacta diretamente a estruturação de redes assistenciais e o acesso do usuário aos serviços.

Tem-se verificado estratégias díspares de descentralização e regionalização, com ênfase nos municípios (sistemas locais isolados) sem um enfoque regional e sistêmico e um destaque tardio da regionalização na política nacional de saúde. Além disso, persistem indefinições quanto ao papel dos governos estaduais e exacerbação de conflitos e dificuldades para a coordenação e cooperação intergovernamental ${ }^{1}$.

Entende-se que o Estado deve contribuir para a constituição e fortalecimento de um sistema de saúde hierarquizado e regionalizado, reunindo os níveis de governo de forma solidária e cooperativa, e exercer papel fundamental na constituição de redes integradas na assistência aos usuários, ressalvando que a construção de redes implica entender que:

[...] a "rede" que integra, organiza, também pode ser (e, muitas vezes, é) a mesma que aprisiona, comprime, constrange; uma "rede" é um conjunto de pontos amarrados, mas deve ser uma trama aberta ao incerto, ao inesperado, ao desestruturado; uma "rede" delimita um platô (não deve ter "cacundas" nem espinhaço), mas para ser multiforme deve ser multiplana, ou seja, abrir-se para as possibilidades de outros "planos", "dimensões", mil platôs.

Uma das pautas prioritárias na agenda da gestão é a discussão sobre as redes de atenção. Entre elas, o Ministério da Saúde vem priorizando a Rede de Atenção Psicossocial (RAPS), objeto de portaria recentemente publicada (Portaria 3088/2011). Esta é definida como a rede de atenção para pessoas com sofrimento ou transtorno mental e com necessidades decorrentes do uso de crack, álcool e outras drogas, no âmbito do Sistema Único de Saúde ${ }^{3}$.

No cotidiano de gestão do SUS, identifica-se, em suma, a ênfase na regionalização e na ativação das redes de atenção para o enfrentamento da persistente e hegemônica fragmentação setorial e intersetorial.

Apesar dos avanços na progressiva e expressiva extinção dos leitos em hospitais psiquiátricos no país e ampliação de serviços substitutivos, muitos desafios ainda persistem no cenário do SUS, particularmente na área da saúde mental ${ }^{4-6}$. Após a necessária e importante Reforma Psiquiátrica, ainda convivemos com uma frágil rede substitutiva, visto que a gestão dos municípios ainda prioriza o cuidado do usuário via internação hospitalar, o que é evidente na pouca oferta de serviços de base territorial.

O debate destas questões e seu aprofundamento e solução delineia-se a partir de um campo que envolve: usuários, famílias, associações, movimentos sociais, trabalhadores da saúde, intelectuais, gestores, entre outros.

A gestão eficaz das redes, dentre elas a RAPS, implica, portanto: trabalhar, rotineiramente, na produção de consensos e decisões político-administrativos, negociar as soluções, e monitorar e avaliar, permanentemente, os processos ${ }^{7}$.

\section{O apoio institucional e o campo}

O debate das redes de atenção vem sendo apoiado pelas diretrizes ofertadas pela Política Nacional de Humanização (PNH). O Ministério da Saúde tem reafirmado esta política como transversal, isto é, que atravessa todas as instâncias do SUS, propondo-se a atuar na autonomia administrativa da gestão da rede de serviços, de maneira a articular processos de trabalho e as relações entre os diferentes profissionais e a população atendida. A PNH destaca a importância de se tecerem redes vivas que sustentem as ações coletivas, substituindo os esforços individuais que se mostram pouco eficazes ${ }^{8}$. 
Na perspectiva deste estudo, enfocamos o apoio institucional como um dispositivo estratégico importante da PNH na tessitura da rede de saúde mental em nível locorregional. O apoio institucional se constitui como um instrumento gerencial que tem sentido de intervenção-oferta, ou seja, é estar junto com os diferentes sujeitos discutindo e analisando os processos de trabalho e intervindo nas formas como os serviços estão organizados ${ }^{9}$. Conforme Campos $^{10-12}$, o apoio pressupõe a existência ou a construção ativa de certo grau de democracia institucional e de cogestão, na perspectiva da construção de autonomia, na transformação do trabalho em saúde e das políticas de saúde.

Com este enfoque, várias questões nos instigaram a necessidade de aprofundamento e análise crítica, como as descritas a seguir: de que modos o apoio institucional à gestão revela-se potente no cotidiano e na produção de redes de saúde mental em nível regional? Como articular Estado e municípios na construção de redes regionais de saúde mental? Que caminhos podem ser trilhados em nível regional para a implicação-inserção do apoiador no cotidiano das redes municipais de saúde mental? Quais as possibilidades de intercessão, articulação, interferência e produção de "redes quentes"13 de produção de vida e cuidado em saúde mental?

Entendemos que a gestão estadual, nível governativo do Estado, deve contribuir para a constituição e fortalecimento de regionalização solidária e cooperativa, e exercer papel fundamental na constituição de uma rede integrada na assistência aos usuários com transtorno mental e uso abusivo de álcool e outras drogas.

As motivações deste estudo estão vinculadas aos caminhos que percorre a gestão estadual, na articulação de uma política de Saúde Mental, a partir de um Departamento Regional de Saúde. Por considerá-lo um ente federado importante no processo de construção do SUS e, ao mesmo tempo, com definições de papéis e funções menos explorados e estudados, nos propusemos a analisar a micropolítica do articulador na função de apoio institucional para vinte e quatro municípios que compõem esta Região de Saúde.

\section{O percurso metodológico}

Apresentamos, neste texto, a vivência, os afetos e a produção de um coletivo de trabalhadores/ gestores da Saúde Mental na Gestão Estadual. Trata-se de um percurso cartográfico vivenciado pela autora na sua atuação como articuladora de Saúde Mental do Departamento Regional de Saúde III Araraquara, vinculada à Secretaria de Saúde do Estado de São Paulo (SES-SP), durante um ano e dois meses (julho/2011 a setembro/2012).

Este estudo está articulado ao referencial teórico-metodológico da pesquisa qualitativa. Buscam-se, através deste, aproximações com a subjetividade humana, no sentido de interpretar, entender significados e sentidos do próprio pesquisador, dos pesquisados e do objeto em estudo. Evidencia a experiência de vida em relação ao conhecimento que cada indivíduo ou coletivo produz em si, no outro e na sociedade. Buscam-se compreender relações, crenças, visões e julgamentos dos diferentes atores sobre a intervenção na qual participam, entendendo que suas vivências e reações fazem parte da construção da intervenção e de seus resultados ${ }^{14-16}$. Trata-se, também, de um estudo de processo e pesquisa-ação. A principal intencionalidade ressalta da análise de um contexto em que uma intervenção ocorreu, e demonstra o rumo de uma intervenção em curso no seu caminho. Pretende-se, também, entender fenômenos sociais e esclarecer intervenções do cotidiano ${ }^{15}$.

Segundo Merhy ${ }^{17}$, todo pesquisador é um sujeito implicado. Mas nem todo sujeito implicado é alvo da sua própria análise. Nessa especificidade, o autor convida à reflexão e institui conceitos sobre o conhecer militante do sujeito implicado. Mais do que a implicação, ele destaca a função epistêmica desse pesquisador durante todo o processo da pesquisa. Há sensações de pertencimentos em que o pesquisador pertence à realidade analisada. A necessidade de estruturar conhecimentos no cotidiano e nas ações dos trabalhadores de saúde reacende o ímpeto de que a militância que transversa esse dia a dia possa ser, também, fim e meio de construção de conhecimento validado pela ciência.

A função do pesquisador é duplamente desafiada: há encontros entre sujeitos implicados, que podem se reconhecer ou se negar, no outro. A validação desse conhecimento é sujeita a várias 
implicações e atravessamentos, que terão de ser analisados mesmo que apresentem contradições. Concomitante, a construção desse conhecimento permite reflexões e novos direcionamentos para coletivos em ação, como sujeito de vários sujeitos, em análise. É dinâmico, sem meio e fim, é plural, é flexível, é processo não linear em suas várias estadas e entradas.

Apesar de essa experiência ter sido vivenciada in loco pela autora deste texto, a escrita do mesmo, em alguns trechos, estará na segunda pessoa do plural, visto que, a todo momento, o segundo autor participou ativamente de todo o processo reflexivo, mediando, inclusive, a atuação da primeira no campo. Enfatizamos que este artigo é um esforço reflexivo e analítico da autora enquanto apoiadora institucional da gestão estadual no DRS III, sob orientação do segundo autor, mediante a proposta de pesquisadores como sujeitos implicados.

Neste estudo, nos colocamos como pesquisadores e sujeitos que interrogam e, ao mesmo tempo, produzem o fenômeno sob análise. Partimos do lugar de sermos gestão e, ao mesmo tempo, objeto de pesquisa, ou seja, o saber ocupa um lugar que mexe no nosso agir e este agir ocupa um lugar que mexe no nosso saber, imediatamente e de maneira implicada.

As interrogações que nos motivam a pesquisar colocam as ações que desenvolvemos em análise, o que nos faz ser objeto de nós mesmos, num processo em espiral e autoanalítico. Ao mesmo tempo, os vários sujeitos que fazem parte das ações também foram focos de análise, num constante movimento do coletivo e do singular, da arte da compreensão e da crítica, dos homogêneos e dos dissonantes. Destacamos a produção de dispositivos que possam interrogar o sujeito instituído no seu silêncio, abrindo-o para novos territórios de significação ${ }^{17}$.

Para a coleta de dados, ressaltemos dois componentes principais na pesquisa:

1) Cartografia: Dado que o gestor-cartógrafo não funciona a partir da aplicação de modelos, e sim a partir de inventar maneiras de gerir os $\operatorname{coletivos}^{18,19}$, interessamo-nos pela processualidade, mais do que os produtos alcançados com a intervenção. Apostamos na (re)invenção dos atores envolvidos no seu agir cotidiano, no seu trabalho vivo em ato.

2) Diários: foi utilizado o diário proposto por Lourau ${ }^{20}$, que identifica três partes componentes do mesmo diário descrito: a) diário de campo: levantamento e agrupamento de dados observados ou a observar; b) diário íntimo: onde se encontram as significações do pesquisador, suas emoções, visões e percepções subjetivas; c) diário de pesquisa: análise dos movimentos simultâneos que se entrelaçam a partir de uma análise teórica.

Além destes, foi incluído o diário institucional ${ }^{21}$, no qual há a descrição de fatos marcantes do cotidiano institucional, buscando assinalar as contradições entre os projetos anunciados e as práticas institucionais.

Para organização do material coletado, utilizou-se a técnica de triangulação, que tem por objetivo abranger a máxima amplitude na descrição, explicação e compreensão do foco em estudo. Esta técnica permite que o pesquisador se dirija: aos processos e produtos centrados no sujeito; aos elementos produzidos pelo meio do sujeito e quem têm incumbência em seu desempenho na comunidade; e aos processos e produtos originados pela estrutura socioeconômica e cultural do macro-organismo social no qual estão inseridos os sujeitos ${ }^{22}$. Em suma, coerência profunda entre método de coleta de dados e técnica de organização e análise.

A análise dos dados foi realizada a partir da aproximação da abordagem hermenêutica-dialética. A hermenêutica e a dialética trazem, em seu núcleo, a ideia fecunda das condições históricas de qualquer manifestação simbólica, de linguagem e de trabalho do pensamento; ambas partem do princípio de que não há observador imparcial, ou seja, consideram o investigador parte da realidade que investiga; ambas se referem à práxis marcada pela tradição, pelo poder, pelos interesses e pelas limitações do desenvolvimento histórico ${ }^{15,23,24}$.

Entendemos que analisar o processo de construção de uma rede temática, no SUS, em sua micropolítica, requer um contínuo vaivém do que denominamos aqui de 'historicidade', ou seja, os acontecimentos presentes estão marcando a história atual e interferirão no futuro. Ao mesmo tempo, sofrem influências diretas e/ou indiretas do que foi o ontem. É uma linha, sem limites periféricos, que contém, em si, o passado, de olho no futuro e em plena realização no agora. No que se refere à opção de ser sujeito implicado em análise, nos aproximamos do entendimento da hermenêutica e da dialética 
da ideia de não-neutralidade e observador imparcial, em especial, quando o objeto de pesquisa faz parte do cotidiano do pesquisador.

Assim, a análise hermenêutica-dialética busca apreender a prática social empírica dos indivíduos em sociedade em seu movimento contraditório ${ }^{23}$. No estudo proposto, a implementação de uma rede de saúde mental vai muito além de criação ou credenciamento de serviços. A trama micropolítica para que isso ocorra depende das pessoas. Destacamos o protagonismo de cada sujeito e dos coletivos envolvidos nesse processo. A busca pela produção de "redes quentes" depende dos trabalhadores, dos gestores e dos usuários que a fazem acontecer na sua cotidianidade.

Há um momento histórico marcado por decisões macropolíticas que trazem, em seu bojo, a formação das redes de atenção. No caso em estudo, estão envolvidos trabalhadores de um Departamento Regional de Saúde e de 24 municípios de sua abrangência que recebem a tarefa da construção da Rede de Atenção Psicossocial, ao mesmo tempo que, em certa medida, a assistência aos usuários em sofrimento psíquico já acontece no cotidiano da atenção em saúde. Há necessidades externas no mesmo platô de necessidades internas. Para análise desses processos, é prioritário, novamente, trazer os conceitos da hermenêutica-dialética no sentido do entendimento dos interesses individuais e coletivos que os unem e interesses específicos que os distinguem e os contrapõem.

Para este grande desafio, buscam-se a crítica, o contraste, a mudança e os macroprocessos pela dialética beneficiada pelo movimento hermenêutico, que enfatiza a compreensão, o acordo e a importância da cotidianidade.

\section{A produção de coletivos: os afetamentos do encontro}

A chegada da articuladora tinha um propósito institucional declarado: "precisamos mexer com a Saúde Mental que está andando muito devagar" (Gestor Regional). No primeiro momento, esta fala não traduzia qualitativamente o contexto. Havia muitos ruídos, muitos sons desarticulados. Era preciso escutá-los! Mas como fazer isso, considerando que a função 'articulador' abrangia a escuta de 24 municípios? Por onde começar?

Muitas vezes, na pressa de ouvir, tal como descrevem Guattari e Rolnik ${ }^{25}$, corremos o risco de compor esses sons com velhos clichês. O grande risco que corríamos era ouvir as queixas que sempre aparecem, cada um com características mais emergenciais do que a cidade vizinha, e realizar ações pontuais com fórmulas mágicas pensadas e produzidas pela gestão estadual.

A decisão capital foi iniciar a escuta por coletivos instituídos. Talvez, nesse

(c) O articulador de saúde mental é responsável por coordenar a Política de Saúde Mental em seu município, desempenhando funções burocráticas e técnico-gerenciais. momento, o 'andar devagar' fizesse algum sentido. O único grupo constituído era o Colegiado de Saúde Mental(c), que há dois meses não se reunia. Este é um espaço colegiado composto pelos articuladores de saúde mental ${ }^{3}$ de cada um dos 24 municípios que abrangem o território do DRS III.

A primeira reunião proposta representou fielmente o contexto imaginado. A parte mais dolorida levantada pelos articuladores era a própria realidade: trabalhadores desvalorizados e desmobilizados; dificuldade de articulação dos serviços especializados com a atenção básica; pouca existência de serviços de referência para municípios menores; serviços de saúde mental insuficientes; indefinição de quem é o paciente da saúde mental; falta de capacitação dos profissionais; frágil comunicação em equipe; a fragmentação do cuidado; pouco entendimento dos preceitos da Reforma Psiquiátrica pelos atores institucionais; gestores pouco sensibilizados; (des) cuidado aos usuários em uso abusivo de álcool e outras drogas; e judicialização da demanda. 
Os problemas estavam na 'ponta da língua'. Mas, quando provocados para olharmos para nós mesmos, para este coletivo, a culpa das dificuldades de produzir mudanças neste contexto (já tão conhecido!) residia no outro, neste caso, ora os gestores municipais, ora os estaduais.

Uma segunda interrogação foi a de como poderíamos nos colocar em análise sem desqualificar o que já foi produzido? A solução encontrada foi olharmos para o nosso íntimo, acolhermos as idiossincrasias do apoiador e deste com o coletivo. Precisávamos nos afetar! Segundo Espinosa ${ }^{26}$, não se sabe quanto podemos afetar e ser afetados, é sempre uma questão de experimentação. E isso teria de ser experimentado no encontro, de abrir-se para o inusitado, para o não prescrito. Abrir-se para a diferença, para explorar a diversidade dos devires e tudo que acompanha esse processo, a exemplo do convite que nos fazem Deleuze e Guattari ${ }^{27}$, quando nos convocam para as desterritorializações provocadas pelo outro, numa ética de respeito à vida e de luta pelo enfrentamento dos problemas concretos.

Precisávamos, enfim, avaliar que movimento este Colegiado estava percorrendo no momento: instituído ou instituinte?

\section{O articulador estadual de saúde mental travestido de apoio institucional: ofertas na análise e a implicação colegiada}

Nos primeiros encontros, percebemos que o articulador de saúde mental, enquanto gestor estadual, deveria exercer o papel de apoiador institucional. Internalizar esse papel, todavia, não era tarefa simples, pois externalizava uma crítica ao modo de fazer gerencial baseado na racionalidade hegemônica ainda presente na Instituição ${ }^{(d)}$, ou seja, externalizava suas implicações. A racionalidade gerencial hegemônica reduz o trabalhador à condição de recurso, alicerçado no aprisionamento da vontade e na expropriação das possibilidades de governar da maioria, restringindo-o a uma dimensão funcional. O trabalho é gerido por comando e controle da gerência com concentração de poder, e o manejo dos processos de trabalho só acontece se houver um centro duro de poder ${ }^{10}$.

A análise das implicações não é dada, entretanto, por meio de um esclarecimento objetivo. Surge na crise, na contradição, na luta, e não na ginástica dialética sobre o papel branco. No nosso caso, de articulador, analisar as implicações de suas pertenças e referências institucionais significava analisar, também, o lugar que ocupa aquele que é um legitimador por suas práticas, nas relações em geral e nas redes de poder, ampliando a análise para além do âmbito da intervenção que está sendo realizada ${ }^{28}$.

$\mathrm{Na}$ experiência real, este convite não foi feito de maneira explícita, tal como temos dissertado neste trabalho, mas em ações, posturas, no modo de produzir do grupo. As experimentações foram sendo realizadas, algumas deram certo, outras nem tanto. Mas o convite da implicação e do afetamento também foi proposto para o articulador estadual. Portanto, não havia 'receitas de bolo', tudo ia sendo construído em processo.

Uma situação indicativa do processo, e que chamou a atenção já no primeiro encontro, foi a tentativa de quebra do poder da condução (e não mediação) do trabalho do grupo. Se a ideia era quebrar o instituído, começamos por não sentar no lugar do diretor. Apesar da conformação da sala da reunião ser propícia, com cadeiras e mesas em roda, o lugar da gerência estava ali 'em destaque'. Não por algo físico ou de mobília que o diferenciasse, mas culturalmente já se sabia o dono daquela cadeira na ponta da roda. É, nesse caso, a roda tinha ponta!

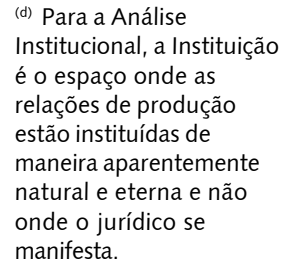


Enquanto não começava a reunião, éramos "apenas" mais um integrante, e os que já estavam no local aguardavam o novo articulador que iria conduzir os trabalhos. Após a chegada de todos, nos apresentamos e, para surpresa de todos, o 'coordenador' estava no meio, e não 'na ponta'.

Decerto, o grupo ficou impactado demais e avaliamos como uma boa estratégia para um primeiro momento. Afinal, Foucault ${ }^{29}$ nos brinda com o argumento de que o melhor conceito para se pensar o poder e suas relações é entender que nenhum ser humano é só objeto, sem nenhum grau de poder. Todo ser humano tem algum grau de poder, de relações, de governo. Só podemos falar de estruturas ou de mecanismo de poder na medida em que supomos que certas pessoas exercem poder sobre outras. Ademais, emprestamos a coerência das ponderações de Campos $^{10}$, que traz o conceito de que o cogoverno é antagônico à ideia de guerra, de revolução, porque o foco não é a eliminação do outro.

A não-ocupação da cadeira da gerência, no nosso caso, não elimina as relações de poder e, segundo o autor supracitado, não deve ser eliminado. O cogoverno vem imbuído de ideais de construção, de reforma, diferente da imagem de guerra, de revolução.

Quando se inicia o trabalho do apoiador, se inicia um novo processo de resistência, de construção ativa de novas instituições, de novos paradigmas na saúde, de nova sociabilidade, de novas relações com base na democracia. A ideia de apoio está, como a entendemos, indissociavelmente ligada à ideia de cogestão dessas relações: cogestão das relações de poder, do trabalho em saúde, inclusive, cogestão do governo de si mesmo ${ }^{10}$.

Após o primeiro incidente provocador, o coletivo foi ganhando corpo, voz e identidade. A alienação dos articuladores pautada pela separação concreta e cotidiana da impossibilidade de participar da gestão foi sendo moldada para o protagonismo e autonomia individual e coletiva. Seguíamos, assim, Merhy ${ }^{19}$, para quem o cotidiano em saúde pode ser palco da produção de novos arranjos no modo de fabricar saúde, onde se configuram novos espaços de ação e novos sujeitos coletivos, bases para modificar o sentido das ações de saúde.

O articulador estadual foi deixando de ser visualizado como o gerente tradicional, e os encontros passaram a estar mais permeados pela cogestão, com divisão de responsabilidades, compromissos com os pactos, o vislumbramento de ações para além das queixas e, especialmente, pela mudança das ações da unidade para a coletividade (os problemas e planos de ação individualizados ganharam menor importância). Discutimos o papel deste articulador municipal: Quem seria ou deveria ser? Que papel desempenhava ou deveria desempenhar no seu município? Como enxergava as relações de poder no seu trabalho, e como fazia ou deveria fazer para transformá-las em ações? Qual o grau de autonomia para desempenhar esta função? Como se colocaria como sujeito protagonista das mudanças que deseja?

Concomitantemente, o Colegiado foi ganhando poder institucional, o que deu certa visibilidade ao movimento e certa sensação de tremor nas estruturas solidificadas dos modos de fazer dos gestores estaduais e municipais. Era chegado o momento dos avanços saírem do espaço protegido do Colegiado!

\section{Os desejos e a construção coletiva dos objetos de investimento}

O apoio institucional realizado pelo articulador estadual esteve sempre pautado na produção de valores de uso. Os três afetos fundamentais da ética ${ }^{26}$ - a alegria, a tristeza e o desejo nos auxiliaram a como 'contagiar', sensibilizar ou afetar um grupo para uma ação ou intervenção necessária em determinado momento. Conforme aquele filósofo, todos têm uma potência de agir, uma força interna e positiva - o Conatus. O existir e agir são modulados pela nossa alegria (aumento do Conatus), tristeza (diminuição do Conatus) e desejo (sentimento que nos determina a existir e agir do nosso jeito). Quando o desejo parte para a ação, ou seja, torna-se consciente, e sabe-se o que se deseja também, possibilita o aumento do Conatus.

Entendendo-nos como coletivo desejante, fomos construindo e propondo agires e existires para além do espaço do Colegiado de Saúde Mental. Eram nossos objetos de investimento!

O coletivo gestor, formado pelos articuladores, sentiu a necessidade de formar outros coletivos, na mesma perspectiva do Colegiado, porém ampliado para a participação dos trabalhadores. Denominamos este espaço de rodas de conversa em Saúde Mental. As rodas surgiram com o objetivo de qualificar as 
ações de saúde mental desenvolvidas nos municípios pertencentes ao DRSIII em resposta à demanda apresentada pelos próprios trabalhadores e pela necessidade de valorização dos mesmos. Foi proposta a realização de rodas periódicas entre os trabalhadores para discussão de temas inerentes ao cotidiano de trabalho das equipes. Uma vez por mês, os trabalhadores se reuniam para discutir a atenção em saúde mental que faziam e a atenção que queriam para a região.

Nos dias das rodas de conversa, a equipe de cada município era 'diluída' em pequenos-grupos diferentes, respeitando-se a diversidade dos serviços em cada roda. A perspectiva das rodas era baseada na proposição da educação permanente, em que as trocas de experiências diversas, realizadas em cada município, eram o motor da construção compartilhada de conhecimento. A mediação do grupo ficou sob responsabilidade do articulador, que, nesta atividade, vivenciava e aprendia o papel de facilitação de grupo. Os temas a serem discutidos na roda seguinte eram sugeridos pelos participantes ao final do encontro. Os disparadores utilizados para iniciar cada discussão (vídeos, situações-problemas fictícias ou reais, depoimentos, narrativas etc.) eram construídos pelo articulador junto ao Colegiado de Saúde Mental. Além disso, eram discutidas as dificuldades e/ou facilidades na mediação do grupo realizada, de modo que, a cada encontro, outros se sentissem mais seguros no desempenho deste papel.

As rodas tiveram início em novembro/2011, e foram realizados 11 encontros até setembro/2012, com participação média de cinquenta trabalhadores. Alguns temas discutidos foram: Conhecendo a rede que temos; Projeto terapêutico dos serviços e singular; Quem é a pessoa que merece o cuidado da Saúde Mental? Saúde Mental e Atenção Básica; Acolhimento em Saúde Mental; O papel do Hospital Psiquiátrico na rede de atenção psicossocial.

No início ou final de cada roda, fazíamos uma avaliação da atividade. O Colegiado entendia a avaliação como necessária e importante para acompanhar as potências e as fragilidades da proposta. Os trabalhadores relataram que as rodas foram um espaço importante de qualificação, preenchendo a lacuna existente de espaços de reflexão da prática, além de possibilitar trocas de experiências entre as equipes - o que tem aperfeiçoado a articulação dos mesmos nos territórios, além de favorecer a constituição e amadurecimento de um coletivo de militância da saúde mental na região. Foram relatados, também, grandes avanços no que se refere aos preconceitos à pessoa em sofrimento psíquico. Apesar destes avanços, analisamos que as rodas não adquiriram potência de capilarização do debate e ação nos municípios, o que deixava distante a discussão para os trabalhadores que não participavam das rodas.

Outro espaço que desafiamos ao nos inserirmos foi o do Colegiado de Gestão Regional (CGR). O DRS III é dividido em cinco CGR, e cada um é composto por secretários de saúde dos municípios agrupados por Colegiado. Por ser um espaço deliberativo da gestão regional, consideramos estratégica nossa participação para que nossas propostas tivessem mais visibilidade e que a Saúde Mental tivesse pauta permanente na discussão, já que esta aparecia esporadicamente e, na maioria dos casos, ligada a processos judiciais contra o município. A publicação da Portaria Ministerial 3.088/2011 que trata de Rede de Atenção Psicossocial (RAPS) nos auxiliou nesse debate.

Esta inserção, contudo, não foi fácil nem aceita rapidamente. Havia certo estranhamento na discussão da política de Saúde Mental. Muitos gestores concebiam uma visão manicomial do cuidado em saúde mental; alguns desconheciam a Reforma Psiquiátrica e, em vários momentos, o assunto era tratado com preconceitos e marginalização. Decidimos que a articuladora estadual faria o papel de 'mediadora' inicial, apresentando a portaria. Apesar do debate superficial na maioria dos CGR, houve um interesse dos gestores pelos investimentos financeiros na implantação dos serviços referendados pela portaria.

Concomitantemente, os articuladores do Colegiado debatiam a Matriz Diagnóstica da Rede de Atenção Psicossocial por CGR, de modo que, no momento oportuno, pudesse ser apresentada e discutida. No período de análise proposto por este trabalho, apresentamos, em dois CGR, a matriz com os serviços da rede regional existentes no território e os que necessitavam ser implantados para um cuidado integral às pessoas em sofrimento psíquico. Consideramos o debate satisfatório e eficiente, já que cada gestor demonstrou entender que seu município teria de fazer uma gestão solidária e cooperativa, pois, no caso da saúde mental, os serviços a serem implantados foram colocados, em sua maioria, como serviços regionalizados devido à baixa densidade populacional da demanda. A natureza 
regional da implantação dos serviços da rede provocou a necessidade de abertura de novas pautas com mais tempo para discussão nas reuniões posteriores de CGR.

O último objeto de investimento ainda não havia sido iniciado até o final deste relato. Trata-se de um projeto coordenado pelo Centro de Desenvolvimento e Qualificação do SUS (CDQ-SUS) e a Articulação de Saúde Mental do DRSIII. O projeto recebeu a denominação de "Tecendo a Rede de Saúde Mental: desenvolvimento dos profissionais e reorganização dos serviços na Região do DRS III Araraquara", com financiamento do recurso da Educação Permanente da SES. Seus objetivos são desenvolver e qualificar o trabalhador e os serviços de Saúde Mental tendo como diretrizes as Políticas Nacionais de Saúde Mental, Educação Permanente e Humanização. Os municípios serão acompanhados por facilitadores que têm o papel de aprofundar as discussões, com ênfase na reflexão sobre a prática. O facilitador deverá conduzir as equipes em processos de problematização, nos quais os coletivos de trabalho deverão propor ações transformadoras, na tentativa de solução dos problemas.

Havia uma grande expectativa sobre o projeto, pois devido a sua natureza de intervenção in loco, junto às equipes, a força do movimento, já iniciado em nível regional, ganharia energia e apoio em nível local. O papel dos articuladores encontrava-se na etapa de informação, conversas e pactuações em nível local, para que este projeto não surgisse 'do nada' às equipes, como em outras situações ocorrera.

\section{Considerações finais}

O agir implicado do apoio institucional descrito em vários momentos possibilitou: a construção ativa de certo grau de democracia institucional e de cogestão na perspectiva da construção de autonomia; a ampliação e capacidade de agir comunicativo e solidário dos sujeitos; a construção de objetos de investimento; a construção de vontade de mudança e de blocos de sujeitos comprometidos; e a criação de rodas e espaços coletivos, seguindo o preconizado por Campos ${ }^{11,12}$.

A função apoio seguiu o caminho da oferta em contraposição à prescrição. A oferta tem como características o fato de que é para ser colocada em análise, ser singular, fazer sentido e ter flexibilidade na busca de contratos sociais. Faz-se necessário que o apoiador vislumbre os sujeitos além de seus loci institucionais ou de seus papéis de trabalhadores e/ou gestores. Implica pensar em gente, com seus imaginários de mundo, e contemplar as singularidades de modo a propiciar cidadania. Os sentidos do fazer vão ao encontro do investimento do que mobiliza, com olhar crítico para as fortalezas e fragilidades. O movimento instituinte é desestruturar as estruturas.

Além disso, o processo de apoio ganhou potência por desencadear essa função 'em cascata'. O devir-apoiador/articulador estadual afetou os modos e maneiras do apoiador/articulador municipal, que afetou o apoiador/trabalhador, que afetou o trabalhador e o gestor; e estes, o usuário.

Enfim, uma rede foi se construindo sem relação de hierarquia, por meio do método da roda (sem ponta!).

Entendemos que este processo abriu um novo complexo de agires para a gestão: novas formas de gerir processos com apoio técnico; construção e fortalecimento do diálogo, vínculos pessoais, afetivos e institucionais; valorização dos articuladores e trabalhadores; construção/fortalecimento de uma rede solidária e cooperativa de saúde mental municipal e regional; e novas formas de pensar e fazer saúde, respeitando os preceitos da Reforma Psiquiátrica. E mais, respeitando os preceitos da luta por saúde integral para todos, com democracia institucional e plenitude democrática. 


\section{Colaboradores}

Aline Barreto de Almeida participou da elaboração do artigo, de sua discussão e redação, e da revisão do texto. Geovani Gurgel Aciole participou da revisão bibliográfica e revisão do texto.

\section{Referências}

1. Viana AL, Lima LD. Regionalização e relações federativas na política de saúde do Brasil. Rio de Janeiro: Contra Capa; 2011.

2. Aciole GG. Redes interfederativas de saúde: um arranjo assistencial instituinte ou mais uma estratégia gerencial? Cienc Saude Colet. 2011; 16(3):1681-7.

3. Ministério da Saúde. Portaria $n^{\circ}$ 3088, de 23 de dezembro de 2011. Institui a Rede de Atenção Psicossocial para pessoas com sofrimento ou transtorno mental e com necessidades decorrentes do uso de crack, álcool e outras drogas, no âmbito do Sistema Único de Saúde. Brasília, DF: MS; 2011.

4. Ministério da Saúde. Reforma Psiquiátrica e política de saúde mental no Brasil. Brasília, DF: MS; 2005.

5. Ministério da Saúde. Legislação em Saúde Mental. 5.ed. Brasília, DF: MS; 2004.

6. Amarante P. Archivos de Saúde Mental e Atenção Psicossocial 2. Rio de Janeiro: Ed. Nau; 2005.

7. Mendes EV. As redes de atenção à saúde. Brasília, DF: Organização Pan-Americana de Saúde; 2011.

8. Ministério da Saúde. Secretaria de Atenção à Saúde. HumanizaSUS: trabalho e redes de saúde. Brasília, DF: MS; 2010.

9. Ministério da Saúde. Secretaria de Atenção à Saúde. HumanizaSUS: documento base para gestores e trabalhadores do SUS. Brasília, DF: MS; 2006.

10. Campos GWS. Um método para análise e co-gestão de coletivos. São Paulo: Hucitec; 2007.

11. Campos GWS. Clínica e saúde coletiva compartilhadas: teoria paidéia e reformulação ampliada do trabalho em saúde. In: Campos GWS, et al., organizadores. Tratado de saúde coletiva. São Paulo: Hucitec; 2006. p. 53-92.

12. Campos GWS. Saúde Paidéia. São Paulo: Hucitec; 2003.

13. Ministério da Saúde. Secretaria de Atenção à Saúde. HumanizaSUS: redes de produção de saúde. Brasília, DF: MS; 2009.

14. Schwandt TA. Três posturas epistemológicas para a investigação qualitativa. In: Denzin NK et al., organizador. O planejamento da pesquisa qualitativa: teorias e abordagens. Porto Alegre: Artmed; 2006. p. 193-217.

15. Minayo MCS et al. Métodos, técnicas e relações em triangulação. In: Minayo MCS, Assis SG, Souza ER, organizadoras. Avaliação por triangulação de métodos: abordagem de programas sociais. Rio de Janeiro: Ed. Fiocruz; 2005. p. 71-103.

16. Turato ER. Tratado da metodologia da pesquisa clínico-qualitativa. Petropólis: Vozes; 2003.

17. Merhy EE [internet]. O conhecer militante do sujeito implicado: o desafio em reconhecê-lo como saber válido. [s.I.], 2004 [acesso 2013 Maio 14]. Disponível em: http://www.uff.br/saudecoletiva/professores/merhy/capitulos-02.pdf 
18. Oliveira GN. Breve percurso para a produção de uma cartografia: devir, intervir, durar, cuidar, narrar, agenciar - ou devir cartógrafo e algumas interfaces com a saúde coletiva. In: Carvalho SR, Ferigato S, Barros ME, organizadores. Conexões: Saúde Coletiva e políticas de subjetividade. São Paulo: Hucitec; 2009. p. 175-90.

19. Merhy EE. Saúde: a cartografia do trabalho vivo em ato. São Paulo: Hucitec; 2002.

20. Lourau R. Uma técnica de análise de implicações: B. Malinowski, diário de etnógrafo. In: Altoé S, organizador. René Lourau: analista institucional em tempo integral. São Paulo: Hucitec; 2004. p. 259-83.

21. Hess R. Momento do diário e diário dos momentos. In: Souza EC, Abrahão MHMB, organizadores. Tempos, narrativas e ficções: a invenção de si. Porto Alegre: Ed. PUCRS; 2006. p. 89-103.

22. Triviños ANS. Introdução à pesquisa em ciências sociais: a pesquisa qualitativa em educação. São Paulo: Atlas; 1990.

23. Minayo MCS. Hermenêutica-dialética como caminho do pensamento social. In: Minayo MCS, Deslandes SF, organizadores. Caminhos do pensamento: epistemologia e método. Rio de Janeiro: Ed. Fiocruz; 2008. p. 83-107.

24. Minayo MCS. O desafio do conhecimento: pesquisa qualitativa em saúde. 9a ed. São Paulo: Hucitec; 2006.

25. Guattari F, Rolnik S. Micropolítica: cartografias do desejo. 7a ed. Petrópolis: Vozes; 2005

26. Espinosa B. Ética. Lisboa: Relógio D'Água; 1992.

27. Deleuze G, Guattari F. Mil platôs: capitalismo e esquizofrenia. Rio de Janeiro: Ed. 34; 1995. v. 2.

28. Lourau R. Sociólogo em tempo integral. Lisboa: Estampa; 1979.

29. Foucault M. Microfísica do poder. 28a ed. Rio de Janeiro: Graal; 2010.

Almeida AB, Aciole GG. Gestión en red y apoyo institucional: caminos en la organización de redes de salud mental en el escenario regional del Sistema Brasileño de Salud (SUS). Interface (Botucatu). 2014; 18 Supl 1:971-81.

Este relato es un registro cartográfico del apoyo institucional en una Secretaría Estadual de Salud para la articulación de la red regional de Salud Mental. El apoyo institucional es una estrategia de la Política Nacional de Humanización en las redes de atención a la salud y un dispositivo de fomento de espacios de gestión conjunta. El relato sigue tres ejes: la producción de colectivos y las consecuencias de las reuniones entre gestores y trabajadores; la acción articuladora del apoyo institucional, las ofertas en el análisis y la implicación colegiada; y los deseos y la construcción colectiva de los objetos de inversión. Con la experiencia de la función de apoyo como camino de articulación y extrayendo los sentidos de ese quehacer por los deseos que movilizan la actuación, se elaboró una mirada crítica hacia los puntos fuertes y débiles de los sujetos institucionales y de los papeles que desempeñan en la producción colegiada del cuidado de la salud mental.

Palabras clave: Gestión en salud. Apoyo institucional. Salud mental. 
